\title{
Developing Global Learning Outcomes in a Civil Engineering Program
}

\section{Dr. Steven J. Burian, University of Utah}

Dr. Steve Burian is an Associate Professor of Civil and Environmental Engineering at the University of Utah. Dr. Burian's career spans two decades during which he has worked in design engineering, as a scientist at Los Alamos National Laboratory, as a professor at the University of Arkansas and the University of Utah, and as a co-founder of Harit Solutions, an engineering design and sustainability consulting firm in India. He has research and teaching expertise related to the engineering of sustainable and resilient urban water infrastructure systems, including water supply, stormwater management, flood control, and wastewater collection. Dr. Burian currently serves as the Director of the USAID-sponsored U.S.-Pakistan Center for Advanced Studies in Water and an Associate Director of the Global Change and Sustainability Center at the University of Utah. During his career, Dr. Burian has been involved with several engineering education endeavors including serving as the Co-Director of Sustainability Curriculum Development at the University of Utah, an Assistant Mentor and Mentor for the ASCE ExCEEd Teaching Workshop, the Secretary/Treasurer for the ASEE Civil Engineering Division, and a frequent collaborator on engineering education projects and ASEE annual conference papers.

\section{Dr. Douglas Schmucker P.E., University of Utah}

Dr. Schmucker has 20 years experience in teaching and consulting. Focused on high quality teaching following the T4E, ExCEEd, and NETI teaching models, he is currently a full-time teaching professional with a focus on online, practice, project, and problem-based teaching methodologies.

\section{Dr. Joshua Lenart, University of Utah}

Dr. Joshua Lenart is an Associate Instructor with the Communication, Leadership, Ethics, and Research (CLEAR) Program at the University of Utah where he teaches technical communications for the Department of Civil \& Environmental Engineering and the Department of Chemical Engineering. He holds a $\mathrm{Ph} . \mathrm{D}$. from the University of Utah in Rhetoric and Writing Studies and an M.A. in English from Montana State University. His research focuses on land management policy in two discrete areas. The first relates to civil infrastructure projects and landscape-scale impacts on habitat, community resilience, and longterm land use planning; the second involves the utilization, conservation, and management of big game wildlife resources.

For the past five years he has led various transdisciplinary teaching and research projects examining land and wildlife resource management conflicts vis-à-vis public policy, assessing stakeholder needs and desires, resource analysis, and collective impact engagement. Currently, he is working closely with several local and national organizations to research and rally opposition against the transfer of federal public lands to state governance.

\section{Mr. Hessam Tavakoldavani, University of Utah}

I have got my Bachelor Science's degree in Civil Engineering from Iran University of Science and Technology, Tehran, Iran. I am currently pursuing my Master of Science's degree in Water Engineering at University of Utah.

\section{Dr. Pedro Romero, University of Utah}

Pedro Romero is Associate Professor of civil engineering.

Dr. Michael E. Barber, University of Utah 


\title{
Developing Global Learning Outcomes in a Civil Engineering Program
}

\begin{abstract}
To best serve their constituencies, civil engineering education programs must adapt to an evolving profession and shifting societal needs. Globalization is an example of a recent key issue affecting civil engineering practice and in turn instigating changes in curricula and pedagogy. The American Society of Civil Engineers (ASCE) convened a summit in 2006 to discuss the changing landscape of the profession responding to globalization and sustainability, among other issues. The summit helped to articulate a vision for the future of civil engineering and initiate the development of the Civil Engineering Body of Knowledge, second edition (BOK2). Inspired by national directives (e.g., ASCE BOK2), an internal programmatic review, and university-level initiatives, the Civil and Environmental Engineering program at the University of Utah conducted a baseline study to inform the enhancement of global learning in the department and the development of global learning outcomes. For the purposes of the study, global learning is defined as the knowledge, skills, and attitudes students acquire to help them comprehend diverse cultures and events, analyze complex systems, appreciate cultural differences, and apply this knowledge as citizens and workers to create sustainable solutions.

The goal of this paper is to report the initial phase of the global learning assessment process and results. The assessment involved identifying global learning activities, documenting perceptions of global learning from student and faculty perspectives, and surveying perceptions of cultural intelligence among students at strategic points in the curriculum. The first part of the assessment involved surveys of the faculty to identify types and amount of learning activities related to global learning. The key finding from the survey was the common narrow perception of global learning as study abroad and international education activities. The second part of the assessment involved surveys of faculty and students in the Fall 2015 and Spring 2016 terms to explore perceptions about students and their self-efficacy associated with global learning. The students surveyed ranged across the curriculum from freshman to graduate students. Interestingly, results indicate that students' self-perception is higher among those earlier in the program, and also confirms our suspicions that student perceptions are higher than faculty perceptions of global learning expectations. The third part of the assessment was conducted using an established cultural intelligence survey instrument. The results indicate the students have higher metrics of global proficiency compared to worldwide norms. But, the student perception changes for the senior students. This is due to one of several reasons, but most likely linked to senior students comprehending global learning better and thus completing the survey with a more realistic assessment of their capacity.
\end{abstract}

This multiple-level assessment has established a baseline for which a longitudinal study of global learning through the curriculum is being conducted. The information helped to identify a need for cross-disciplinary engagement, create draft global learning outcomes consistent with ASCE's BOK Professional Outcomes, and create preliminary ideas for a professional development plan for the faculty to support improved global learning. 


\section{Introduction}

As globalization has expanded, the need has arisen for civil engineers to be able to design infrastructure considering a systems perspective, especially those able to transcend technical concerns and consider cross-cultural factors. ${ }^{1}$ The ASCE BOK2 captures the essence of this need in an array of civil engineering education student learning outcomes. The BOK2 is organized into three broad areas: foundational, technical, and professional. Foundational elements include mathematics, natural sciences, humanities, and social sciences. The technical elements are numerous and range from mechanics to design to project management and sustainability. Professional elements include communication, public policy, globalization, leadership, teamwork, attitudes, and more.

Effectively interacting with a culture, or a particular society or group, in the civil engineering profession requires elements described in all three areas of the BOK2. Civil engineering students having achieved appropriate levels of global learning will have the knowledge and skills necessary to comprehend diverse cultures and events, analyze complex systems, appreciate cultural differences, and apply this knowledge as citizens and workers to create sustainable solutions. Global learning outcomes provide a way to assess achievement of this knowledge and these skills.

Although programs vary among the different universities and knowledge communities, they share common fundamental targets for global learning outcomes. As such, we understand global learning as "the process of diverse people collaboratively analyzing and addressing complex problems that transcend borders." ${ }^{2}$ It is important to note that borders in this context is not limited strictly to geographic borders, but, rather, involves a more holistic notion of the term to signify any social, political, geographic, or economic border that exists amongst a given community. In terms of pedagogical practice, global learning can be further defined in terms of those strategies which "enable groups to determine relationships among diverse perspectives on problems and to develop equitable sustainable solutions for the world's interconnected human and natural communities." ${ }^{2}$ Within the context of this study, global learning acts as a rallying point to conjoin individual faculty efforts to increase students' awareness, perspective, and engagement with global themes and concepts germane to our department as well as the broader community of civil engineering practice.

Institutions of higher education are incorporating global learning outcomes into their curricula. There are numerous examples, but most are focused on international experiences, e.g., the University of Rhode Island International Engineering Program (IEP). ${ }^{3}$ The Rhode Island IEP seeks to train engineers to be able to operate in the international workplace by earning one degree in an engineering discipline and one in a foreign language. In a similar, but more focused way, the Georgia Institute of Technology, School of Civil and Environmental Engineering uses a program called the Joe S. Mundy Global Learning Endowment ${ }^{4}$ to provide an international learning experience for students that may include international research or a summer-long study abroad. In addition to the significant resources often needed to promote study abroad, there are other curricula actions that affect the perceived ability of institutions to promote globalizationrelated learning outcomes. For example, several institutions are revamping their core curriculum to include an emphasis on globalization while others are creating interdisciplinary courses with 
an international "thread" linking subject content from disciplines as diverse as fine arts, social sciences, natural sciences, and economics.

Institutions are also developing globally-oriented programs specifically for engineering students. Synthesis of studies on global learning in engineering programs suggests institutions typically elect to improve an existing course, design an elective course that embeds global dimensions into disciplinary-specific content, and/or include a significant intercultural experience. In some cases, institutions have designed vehicles for global learning as co-curricular and extra-curricular activities, as is the case for engineering-specific global learning communities (e.g., Purdue University Global Engineering Cultures and Practice Learning Community). Programs have generally sought to immerse students in one or more cultures different from their own, which, as a result, allows students to experience situations where they feel out of their element, and need to adapt to this feeling to gain confidence. In addition, students are forced to demonstrate a level of language proficiency appropriate to the type of experience. Although most think of a global learning opportunity as study abroad, there are programs using non-study abroad activities to achieve desired outcomes. These include using service learning with a connection to international, capstone projects, elective courses, and research opportunities. Given the wide array of experience that can be achieved from global programs, institutions are seeking to select appropriate programs to match their global learning outcomes. For instance in 2015, the faculty of the University of Portland introduced three sets of outcomes related to global engineering. ${ }^{5}$

Institutions remain in search of methods to determine if global learning programs are helping students to develop attributes that meet program objectives, accreditation requirements, and the needs and desires of prospective employers. ${ }^{6}$ Studies have investigated the effectiveness of a range of activities. ${ }^{7,8}$ In general, programs are seeking to achieve global learning outcomes related to 1) cultural knowledge, 2) foreign language skills, and 3) openness to new experiences and other cultures, which can be dependent on many factors. For example, according to the results of a recent article in the Chronicle of Higher Education, the study abroad benefits for students depend on duration and destination of travel, therefore requiring intentional strategies to achieve the desired outcomes. ${ }^{9}$ However, regardless of the duration, place and general outcomes of a program, a tool to measure the effectiveness of the plan is needed. Some institutions develop an inventory of existing assessment tools to check whether there are appropriate ones. For instance, Georgia Institute of Technology selected the Intercultural Development Inventory (IDI) in 2005 because of the lack of other validated instruments available at that time. According to Assessment Director Jonathan Gordon, it has probably created the largest single institutional database for the IDI. ${ }^{6}$

Given the public nature of the field of civil and environmental engineering, it is our view as educators that we have a responsibility to challenge our students to become more active, global citizens in a collective effort to improve the quality of existence for the global community. For civil engineers, such efforts come in many forms, e.g.: improved treatment, reclamation, and delivery systems for clean drinking water; upgrading transportation systems including road, bridge, and public transit systems for maximum safety and efficiency; or technologicallyinnovative methods for capturing, utilizing, and developing natural resources for equitable and sustainable energy production systems. Such an outlook echoes Martha Nussbaum's sentiment that students, like all citizens, "cannot think [...] on the basis of factual knowledge alone," 10 but 
must learn to see past borders and work to cultivate well informed and nuanced responses to an increasingly globalized world. Toward this end, it is no longer appropriate for departments of civil engineering to simply carry on with business as usual where it concerns the cultivation of technical expertise; instead, civil engineering faculty have an additional mandate to help students participate in the multiple roles in which they will participate as practicing engineers. Global learning, in this sense, extends beyond a simple definition of the term to denote a preoccupation with internationalism, but instead connotes a whole host of ideas, which Kevin Hovland argues, better prepares students to apply their technical expertise, and thus open "the door for democratic practice and social responsibility at the experiential level." 11

The project introduced herein is seeking to improve the ability of Civil and Environmental Engineering graduates from the University of Utah to have an impact in a global society by applying their knowledge, skills, and aptitudes in local and global contexts. This follows from the recent University of Utah, Office for Global Engagement Global Learning Across the Disciplines (GLAD) initiative and aligns with the definition of global learning "as the knowledge, skills, and attitudes that students acquire through a variety of experiences that enable them to understand world cultures and events; analyze global systems; appreciate cultural differences; and apply this knowledge and appreciation to their lives as citizens and workers". ${ }^{2}$ Tasks for the GLAD project include:

1. Facilitate faculty and student dialog on global learning.

2. Compile a summary of global learning activities and assessment techniques.

3. Collaboratively develop course-level and program-level global learning outcomes.

4. Identify gaps and make recommendations for enhancing global learning of graduates.

5. Design strategies to enhance global learning of graduates.

6. Recommend a framework to assess effectiveness of global learning activities.

This paper presents details of the process used to document and assess global learning and the baseline results. The assessment components reported herein involved identifying global learning activities, documenting perceptions of global learning from student and faculty perspectives, and surveying perceptions of cultural intelligence among students at strategic points in the curriculum.

\section{Methods}

\section{Global Learning Activities Survey}

Numerous global learning inventories have been completed, but all that could be located have been conducted at a broad institutional level. ${ }^{11}$ We decided to conduct a basic inventory of global learning activities to ascertain the general conceptual understanding and practical implementation of global learning. The faculty of the Department of Civil and Environmental Engineering at the University of Utah were surveyed for examples of types of learning activities they implement that help students achieve global learning outcomes. The faculty were provided the following definition of global learning from Olson et al. ${ }^{13}$

"knowledge, skills, and attitudes that students acquire through a variety of experiences that enable them to understand world cultures and events; analyze global systems; appreciate 
cultural differences; and apply this knowledge and appreciation to their lives as citizens and workers"

Then they were asked to list and describe learning activities, the relevance to global learning, and how it is assessed. Faculty were not guided to provide international educational experiences, although it was suspected that most faculty would align global learning with international.

\section{Global Competency Inventory}

Faculty and students in the Department of Civil and Environmental Engineering were asked to complete a survey assessing the global competency of students. Professors rated student competency and students rated their own competency. The Global Competencies Inventory (GCI) developed by the Kozai Group ${ }^{14,15,16,17,18}$ is designed to assess personal qualities associated with effectiveness in environments where there are cultural norms and behaviors different from one's own. The information contained in the feedback report can provide a basis for understanding both current competencies as well as point to opportunities for future development and growth.

The report focuses on three main factors of intercultural adaptability:

- Perception Management

- Relationship Management

- Self-Management

Perception management considers the processes by which perceptions and judgments are made, as well as the ability to accurately make sense of ambiguous situations and to be inclusive of differences, e.g., nonjudgementalness, inquisitiveness, tolerance of ambiguity, cosmopolitanism, and interest flexibility. Relationship management considers self-awareness, the ability to attend to yourself and others, and the application of sound interpersonal skills to deal with people from different cultures or ethnic groups. Self-management consists of personal traits known to be essential for effective coping when faced with the challenges and personal demands of intercultural situations such as optimism, self-confidence, self-identity, and emotional resilience. A copy of the GCI is included in Appendix A.

\section{Cultural Intelligence Survey}

A need associated with the work reported here includes a call for increased global cultural awareness on the part of civil engineering graduates and practitioners. ${ }^{19,20}$ The Association of American Colleges and Universities (AAC\&U) "has identified global knowledge, ethical commitments to individual and social responsibility, and intercultural skills as major components of a $21^{\text {st }}$ century liberal education. ${ }^{21}$ It is natural to consider cultural awareness within an international, or global, context. A more holistic approach taken by the co-authors considers global to also mean a big-picture view. The cultural intelligence community appears to embrace such a view point and considers global diversity and cultural awareness to have international and "domestic" diversity. ${ }^{22}$ International diversity focuses on cultural awareness and differences associated with nation-states (or ethnicities) whereas domestic diversity focuses not on boundaries related to international aspects but on cultures within business, social, education, and professional contexts. For example, a typical civil engineering consulting office in a large U.S. city may employ staff from across different parts of the world (international diversity). It is 
perhaps equally important for the company to be aware of and respond to the differences that exist between businesses, engineers, technicians, and office staff cultures (domestic diversity).

Cultural intelligence and global learning, then, pertains to far more than a simple understanding and recognition of how to work with different ethnicities. The co-authors are particularly interested in and investigating cultural intelligence in the framework of preparing civil engineering graduates to enter the workplace. Several questions that abound include: What is cultural intelligence? How can it be taught? How can it be assessed (measured)? And how does it complement a civil infrastructure perspective? A variety of initiatives to develop global learning related outcomes and rubrics have been developed across the United States such as AAC\&U's Valid Assessment of Learning in Undergraduate Education (VALUE) initiative. ${ }^{23}$ "The VALUE rubrics include Inquiry and Analysis, Critical Thinking, Creative Thinking, Written Communication, Oral Communication, Quantitative Literacy, Information Literacy, Reading, Teamwork, Problem Solving, Civic Knowledge and Engagement - Local and Global, Intercultural Knowledge and Competence, Ethical Reasoning and Action, Global Learning, Foundations and Skills for Lifelong Learning, and Integrative Learning. Since their release in the fall of 2009, the rubrics have become a widely referenced and utilized form of assessment on campuses across the United States and internationally.

In simple terms, one may view intelligence as comprised of three spheres - mental ability (IQ), emotional intelligence (EQ), and cultural intelligence (CQ). In many cases with acceptable minimum levels of IQ and EQ, the critical sphere for success is cultural intelligence ability.

Cultural intelligence (commonly abbreviated CQ for cultural quotient), is a measure of the capacity to operate and adapt effectively in intercultural settings ${ }^{24}$. CQ was the focus of this project and assessed using the evidence-based assessment instrument created by Linn Van Dyne and Soon Ang and available through the Cultural Intelligence Center (http://www.culturalq.com/). The basis of the CQ Survey employed for this project is four components:

- $\quad$ CQ Drive - the level of interest, drive, and motivation to adapt interculturally

- $\quad$ CQ Knowledge - the level of understanding about how cultures are similar and different

- $\quad$ CQ Strategy - the degree to which one is mindful, aware, and able to plan for multicultural interactions

- $\quad$ CQ Action - the degree to which one can appropriately change verbal and nonverbal actions by drawing upon a repertoire of behaviors and skills

The survey provides information on cultural intelligence (CQ) and cultural value orientations. Research behind the survey shows consistently that higher CQ relates well to:

- more effective cross-cultural adaptability and decision-making

- enhanced job performance

- increased profitability and cost-savings

- reduced attrition

The CQ Survey takes a broad perspective of cultural diversity to include intercultural interactions that occur domestically in addition to internationally. Domestic cultural diversity is embodied in organizational, functional, gender, geographic, race, ethnicity, and other subgroups. 
The CQ Survey used for this project was the Self-Assessment Basic Plus version, which consists of approximately 35 questions measuring the individual's perception of capacity in the four CQ areas of Drive, Knowledge, Strategy, and Action. The survey required approximately 20 minutes to complete. The survey was administered to students in four undergraduate courses:

1. Introduction to Civil and Environmental Engineering - freshman course (45 students)

2. Statics - primarily sophomore students (39 students)

3. Technical Communication - primarily junior students (14 students)

4. Senior Design - primarily senior-level students (11 students)

After completion of the survey, each participant receives a personal feedback report that summarizes the results, and places the individual against the world norms (population of survey respondents over time) (see Figure 1).

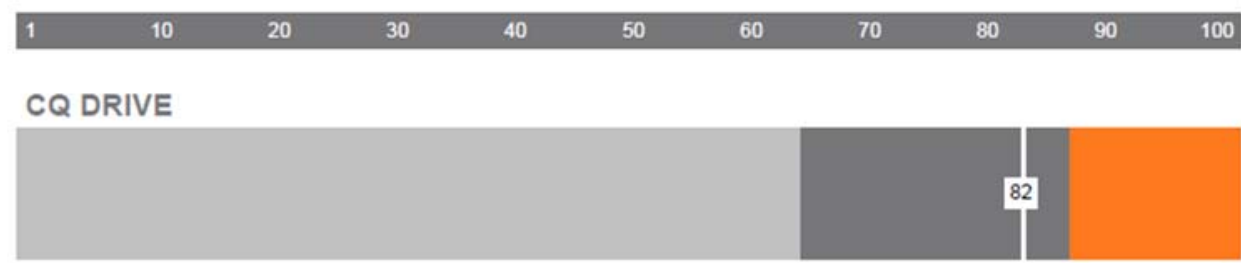

CQ KNOWLEDGE

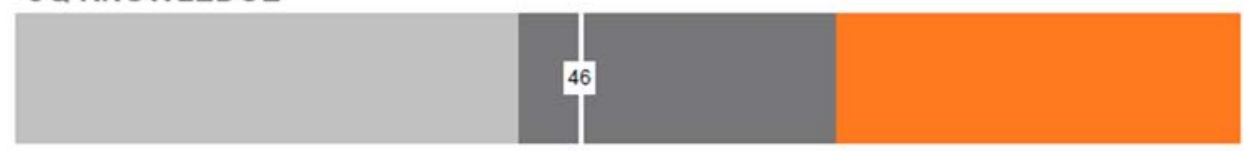

CQ STRATEGY

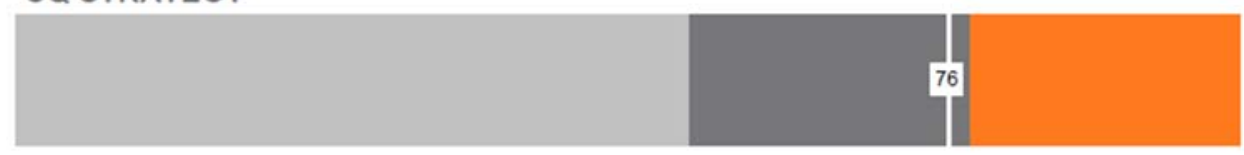

CQ ACTION

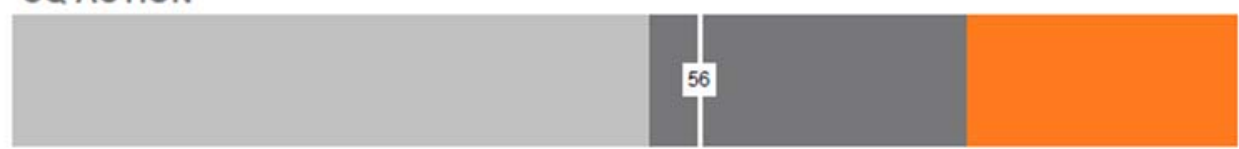

Figure 1. Sample result summary of CQ for an individual relative to the population. Scale across the top is $0-100$ (percentile of survey population), light gray represents the lower $25 \%$ of the world wide norms, the dark gray represents the middle $50 \%$, and the orange demarks the top $25 \%$ of the world wide norms. The line and box showing the score represents the individual or group value based on the survey responses.

The individual report further breaks down the score into sub-dimensions for each component (Drive, Knowledge, Strategy, Action). A group report was also generated by the Cultural Intelligence Center that placed the group (freshman, sophomore, junior, senior) taking the survey among the world wide norms. 


\section{Results}

\section{Global Learning Activities}

Observations from the faculty descriptions of learning activities indicate a wide array of activities, but limited comprehension about how the activities can help achieve global learning. Once observation was the inventory clearly indicated that the majority of faculty members (and all that are not co-authors of this paper) perceived global learning to be associated with international activities. A second observation was the lack of assessment of global learning. Of the 15 respondents completing the learning activity sheet, only two documented assessment practices (and both of them are co-authors of this paper). And even those that indicated assessment the focus was not a defined global learning outcome, at least not one explicitly considered a priori (it is important to note that the Department of Civil and Environmental Engineering similar to most departments in the U.S. does not have established global learning outcomes). In sum, the learning activity sheets suggested faculty members are, in general, interested in global learning, have the opportunity and interest to incorporate into courses, but need guidance on the broader concepts of global learning beyond study abroad or international exposure.

\section{Global Competencies (GC) Inventory}

The GC survey was completed by 15 faculty members (although not all parts were completed by all faculty members), 17 freshman, and 11 seniors in the Department of Civil and Environment. The faculty generally perceived students to have moderate competency in each of the three categories - Perception Management (PM), Relationship Management (RM), and SelfManagement (SM) (Figure 2). Students rated themselves higher in GC compared to the faculty. The ratings from freshman students were essentially the same as the ratings from senior students. The average faculty and student (freshman and senior combined) scores were 3.6 (Moderate) and 4.5 (Moderate to High), respectively. The faculty rating of SM was 4.0, which was the closest rating to student rating of the three categories.

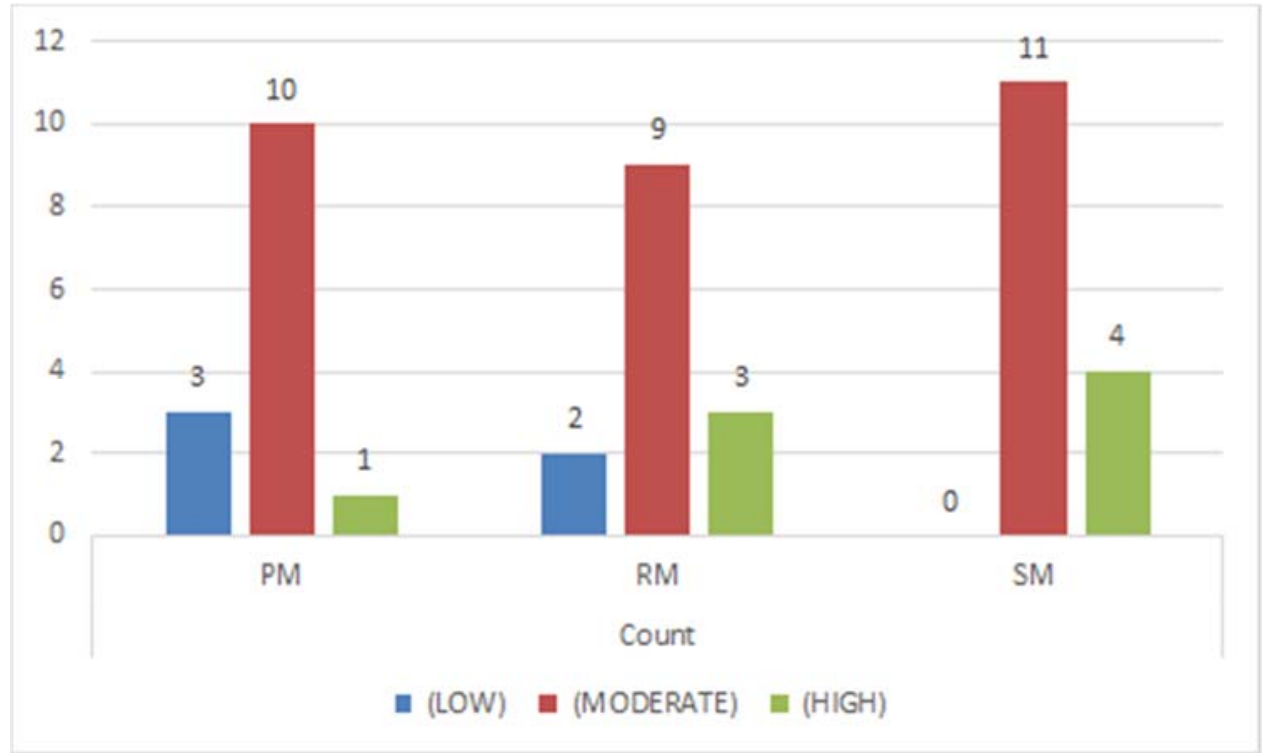

Figure 2. Summary of student GCI completed by faculty members responding to survey. 


\section{Cultural Intelligence Survey}

The survey of students was completed for the four courses included in this phase of the project. Table 1 summarizes the characteristics of the respondents. The number of students reduced in each level partly because of the number of sections and number of offerings per year, and the randomness of enrollment in any given semester. It is interesting to note the percent of students speaking two languages generally increases as students progress through the curriculum with nearly HALF speaking two languages when they reach their senior year. This corresponds to the self-rated amount of prior intercultural experience increasing from moderate to large as students progress from freshman to senior year.

Table 1. Characteristics of CQ survey respondents in Civil and Environmental Engineering.

\begin{tabular}{|l|l|l|l|l|}
\hline Course & Respondents & $\begin{array}{l}\text { Gender } \\
\text { Composition }\end{array}$ & $\begin{array}{l}\text { Percent } \\
\text { Speaking 2 } \\
\text { Languages }\end{array}$ & $\begin{array}{l}\text { Amount of Prior } \\
\text { Intercultural } \\
\text { Experience }\end{array}$ \\
\hline $\begin{array}{l}\text { Introduction to } \\
\text { CEE (freshman) }\end{array}$ & $45 / 45(100 \%)$ & $\begin{array}{l}64 \% \text { Male / } \\
34 \% \text { Female }\end{array}$ & $22 \%$ & Moderate \\
\hline $\begin{array}{l}\text { Statics } \\
\text { (sophomore) }\end{array}$ & $39 / 39(100 \%)$ & $\begin{array}{l}77 \% \text { Male / } \\
23 \% \text { Female }\end{array}$ & $36 \%$ & Moderate \\
\hline $\begin{array}{l}\text { Technical } \\
\text { Communication } \\
\text { junior) }\end{array}$ & $13 / 15(86 \%)$ & $\begin{array}{l}69 \% \text { Male / } \\
31 \% \text { Female }\end{array}$ & $30 \%$ & Moderate \\
\hline $\begin{array}{l}\text { Senior Design } \\
\text { (senior) }\end{array}$ & $11 / 11(100 \%)$ & $\begin{array}{l}73 \% \text { Male / } \\
27 \% \text { Female }\end{array}$ & $45 \%$ & Large \\
\hline
\end{tabular}

Figures 3-6 present the summary CQ profile for the students in the Introduction to Civil and Environmental Engineering, Statics, Technical Communication, and Senior Design courses, respectively. The results show that the students surveyed have self-rated CQ greater than the worldwide norms in all categories, except CQ Action, for freshman and sophomore year. But for the senior year course, the students rated themselves below the worldwide norms. The students in Senior Design also rated themselves as lower than freshman and sophomore year students when comparing the ratings across courses. This is peculiar given the senior students self-rated their number of languages spoken as higher as well as the amount of intercultural experience. A potential explanation for this trend is that as student intercultural experiences increased through the curriculum their norm for rating their capability in the four areas also increased leading to a lower relative self-rating. 


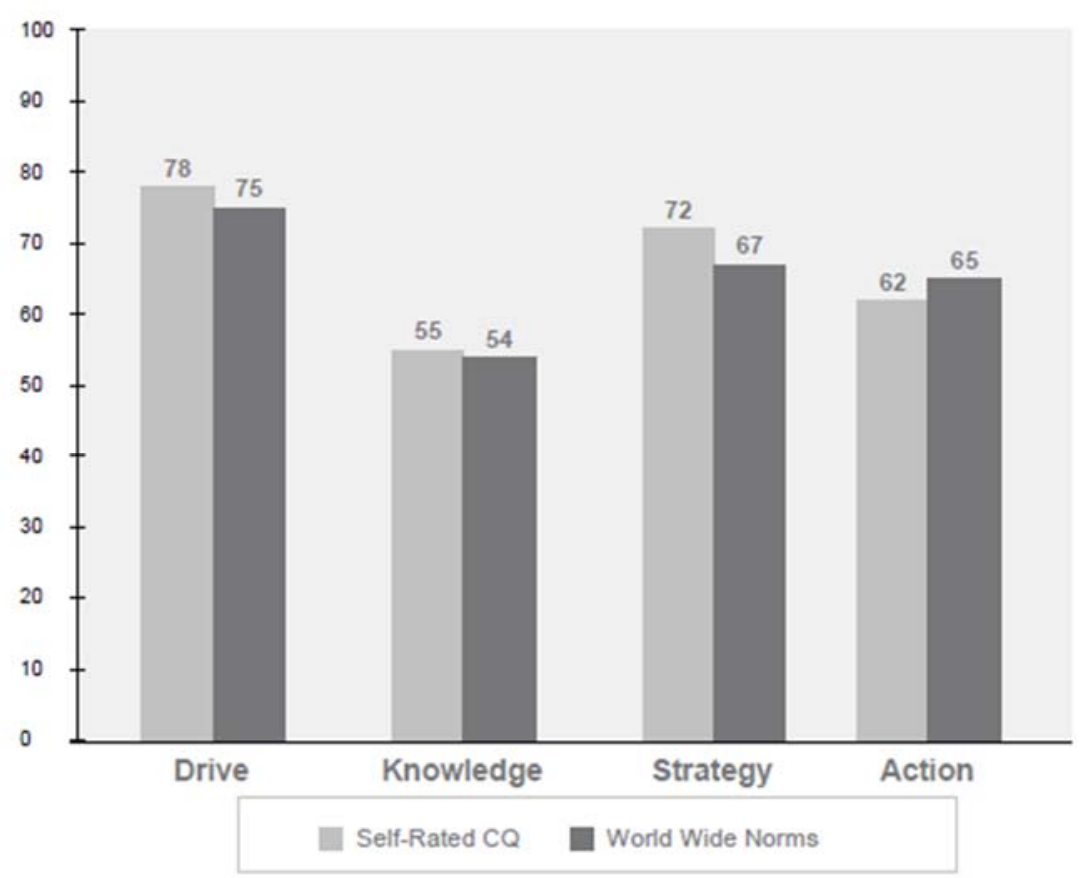

Figure 3. Summary group CQ profile against the world wide norms for the students in the Introduction to Civil and Environmental Engineering (freshman) course.

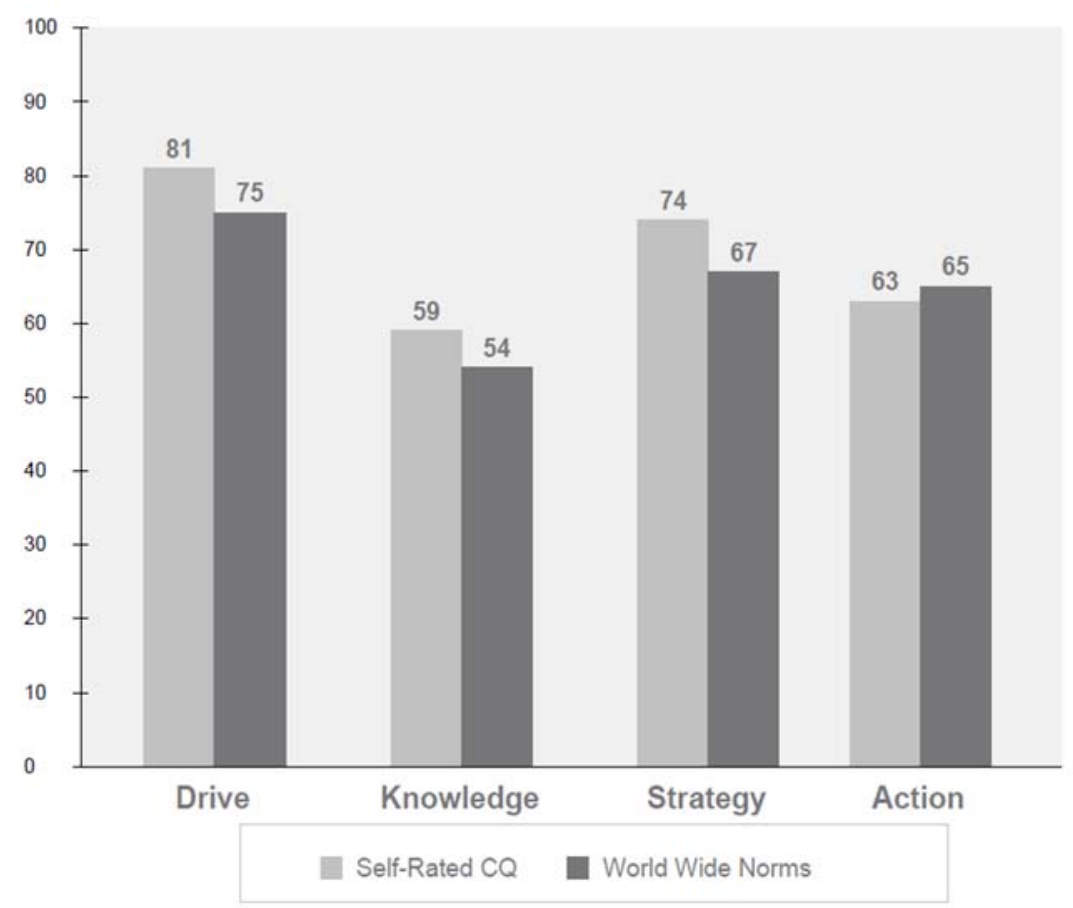

Figure 4. Summary group CQ profile against the world wide norms for the students in the Statics course (sophomore). 


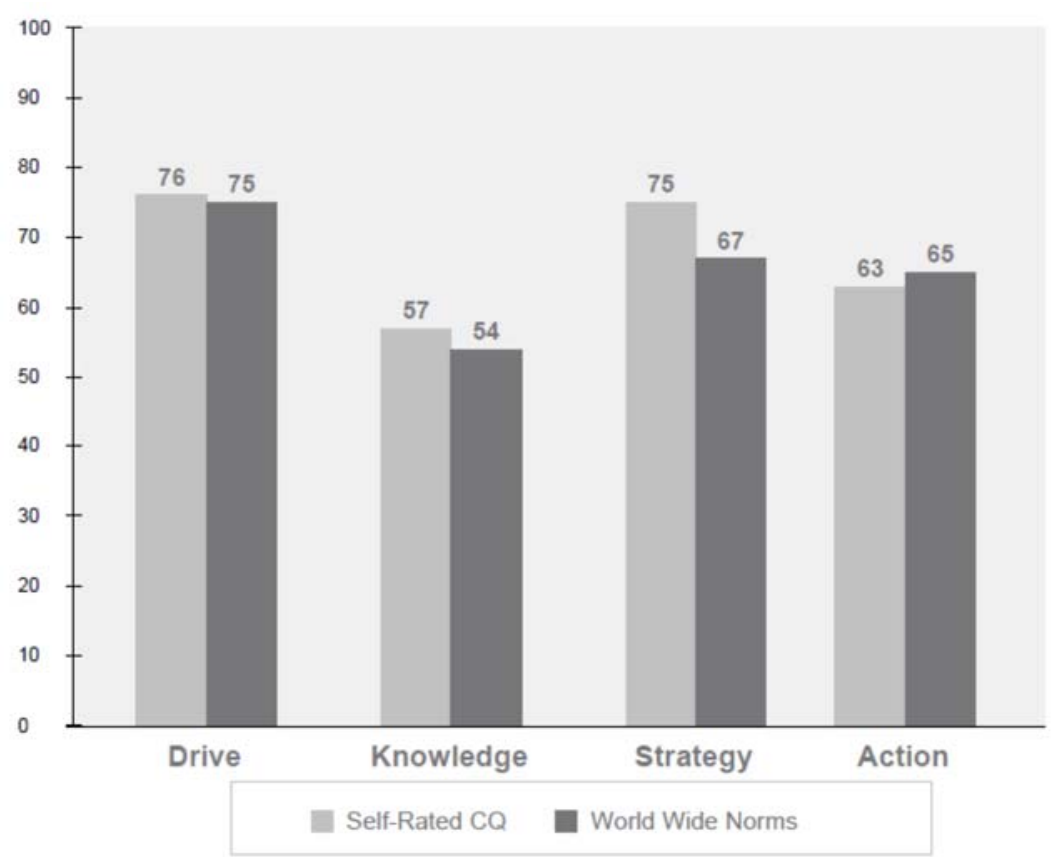

Figure 5. Summary group CQ profile against the world wide norms for the students in the Technical Communication course (junior).

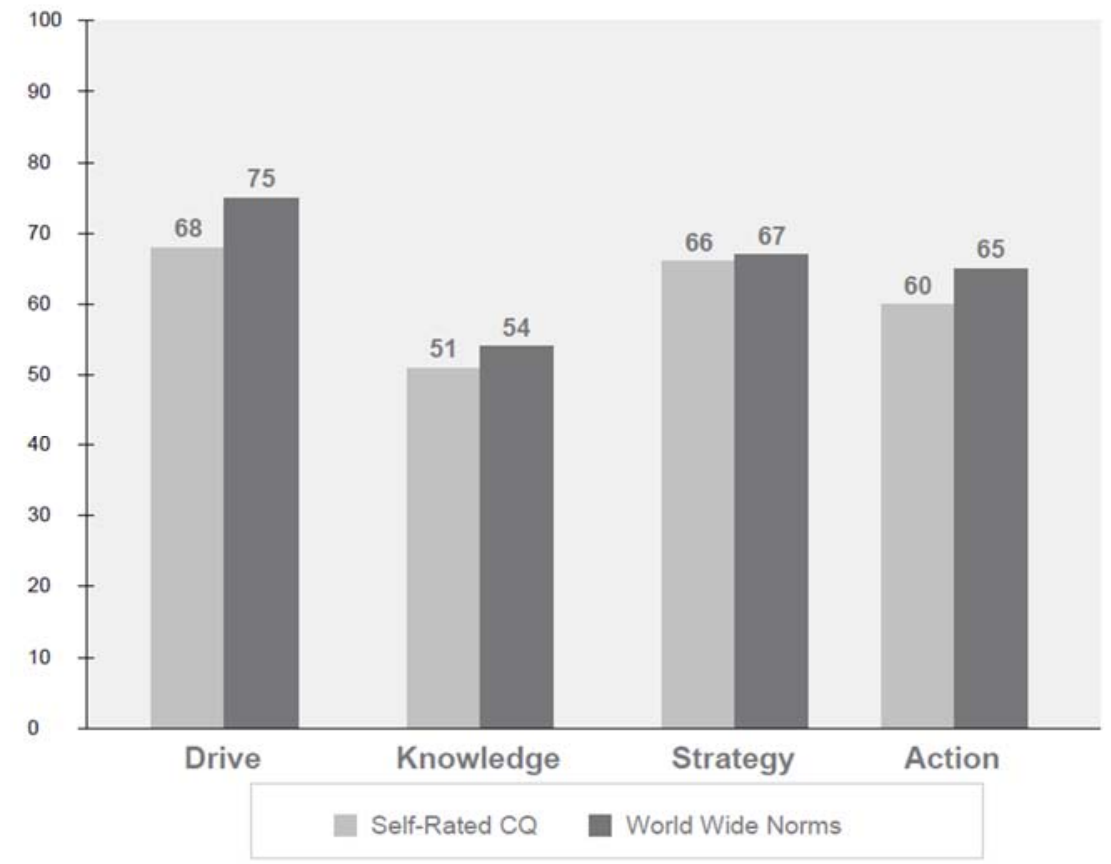

Figure 6. Summary group CQ profile against the world wide norms for the students in the Senior Design course (senior). 
Survey responses are also broken down into relative levels of low, moderate, and high. Scores in the low category are in the lower $25 \%$ of the world wide norms while scores in the moderate and high categories are in the middle $50 \%$ and highest $25 \%$ of the world wide norms, respectively. Figures 7-10 present the distribution of individual student results in the three categories of low, moderate, and high for the four surveyed courses. The results suggest students improve their drive, strategy, and action but remain approximately the same for knowledge from freshman to sophomore years. Similar to the observation from Figures 3-6, it is noted that the trend reverses for senior students and their self-rated capacity in all categories reduces.

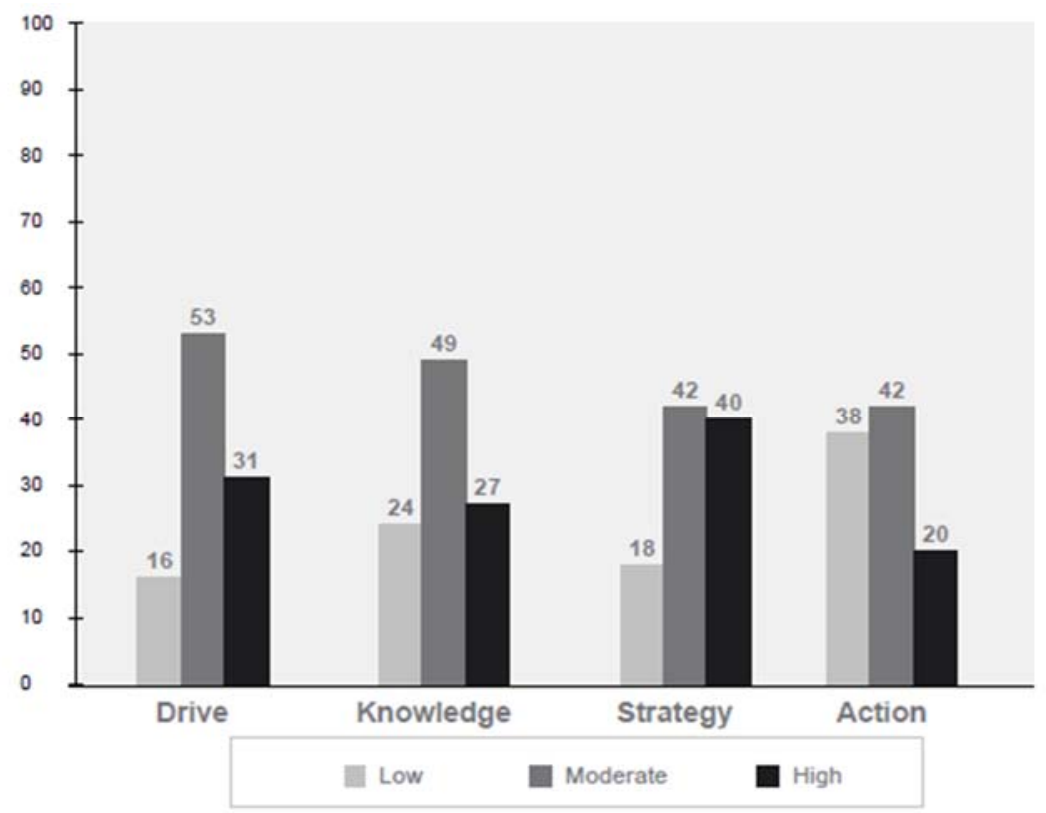

Figure 7. Percent of low, moderate, and high scores for the students in the Introduction to Civil and Environmental Engineering course (freshman). 


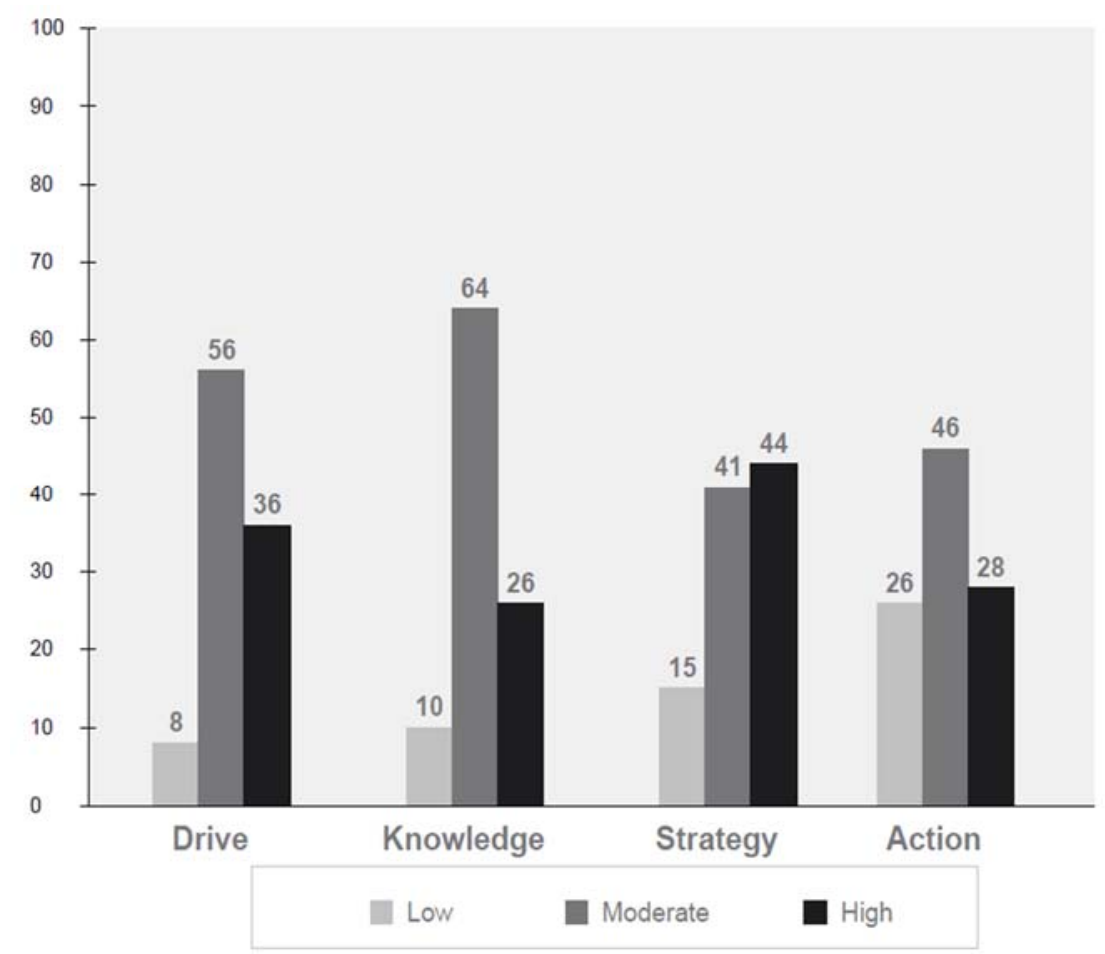

Figure 8. Percent of low, moderate, and high scores for the students in the Introduction to Statics course (sophomore).

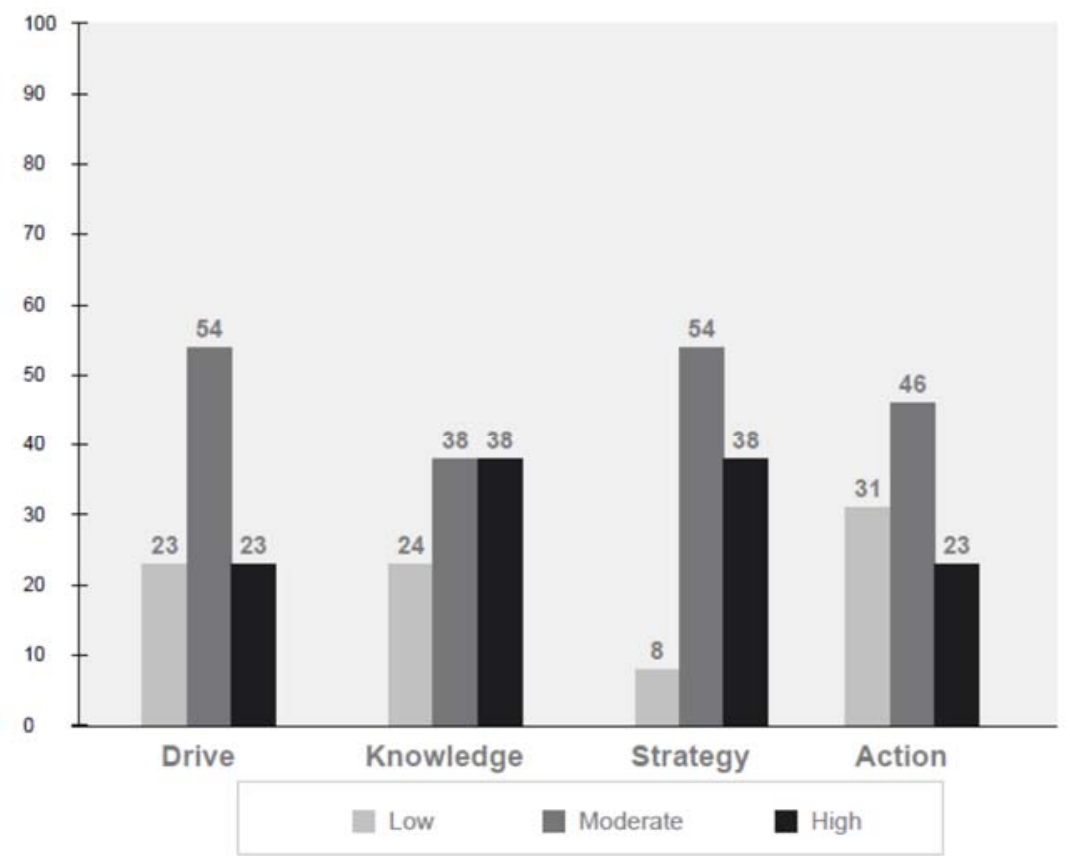

Figure 9. Percent of low, moderate, and high scores for the students in the Technical Communication course (juniors). 


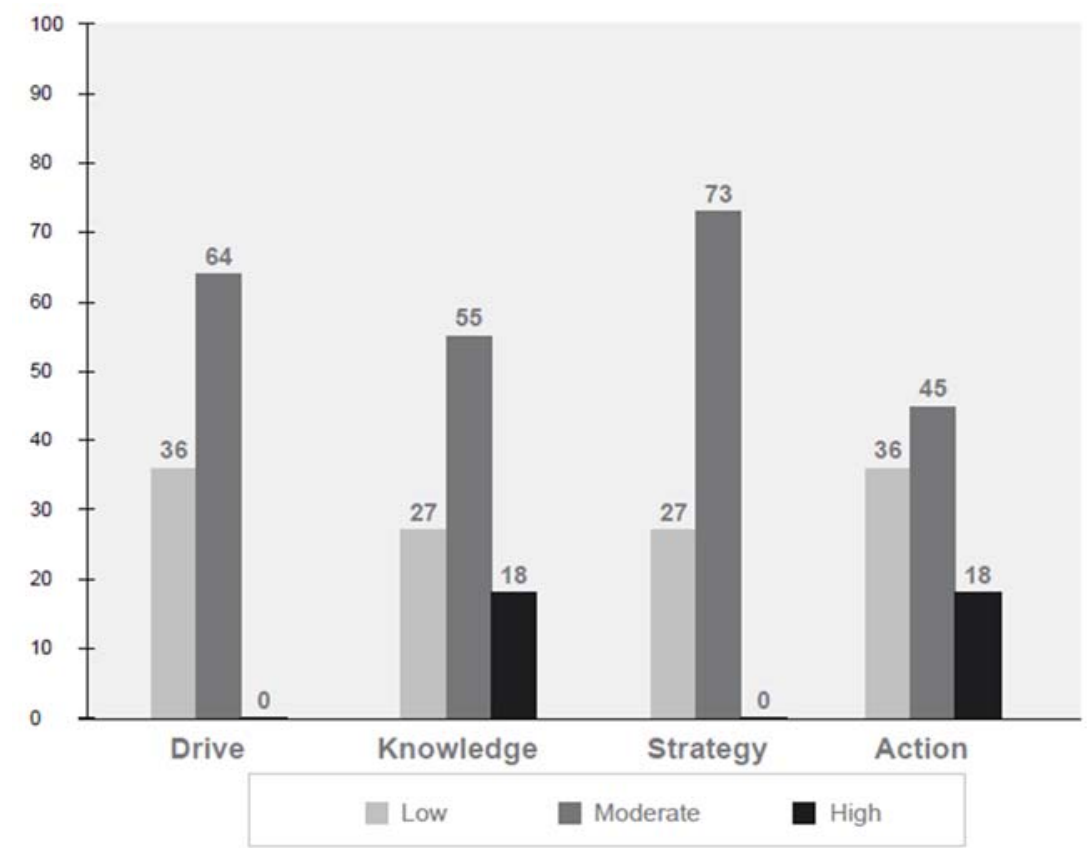

Figure 10. Percent of low, moderate, and high scores for the students in the Senior Design course (seniors).

\section{Conclusion}

This paper presented the results of a baseline study to inform the enhancement of global learning in the Department of Civil and Environmental Engineering at the University of Utah, and the development of global learning outcomes.

The results of the survey of global learning activities suggests faculty members generally incorporate learning activities into their courses with the potential to achieve global learning outcomes, but they do not have an awareness or operational implementation of global learning beyond international exposure (e.g., study abroad). A more comprehensive global learning inventory was found to be needed to identify activities that fit a broader concept of global learning consistent with cultural intelligence measures.

The results of the Global Competencies Inventory suggests faculty members perceive student competencies lower than student self-rating. There was essentially no difference in self assessed global competencies between freshman students and senior students.

The preliminary results of the CQ survey indicate self-rated CQ similar to the world wide norms (in general in the middle quartiles). Trends in self-rating from freshman to senior year decreased, although the perceived amount of intercultural experience has increased. This can be attributed to one of several factors: 
1. students gain an improved comprehension of the knowledge and skills needed for intercultural experience as they progress through the program, and thus rate themselves lower relative to the rating from students earlier in the program,

2. faculty are not focusing their learning activities sufficiently on global learning outcomes,

3. students entering the curriculum have experienced more learning activities in response to BOK2 and other initiatives such that freshman and sophomore students are achieving global learning outcomes at a higher level compared to their predecessors five years earlier.

Overall, this work is leading to the development of global learning outcomes in the University of Utah Department of Civil and Environmental Engineering. The global learning outcomes are being designed to merge the growing international opportunities with the needs of the local civil engineering profession. Creative learning activities are needed to translate outcomes from international learning experiences to serve the local professional market.

A key broader impact of the project is the development, testing, and refinement of techniques to efficiently and effectively assess a broad definition of global learning in civil and environmental engineering programs. The baseline study presented herein used three measures. Reflection on the measures combined with reviewer comments indicates a direct measure of student learning remains a key missing component, but one that requires a much more significant effort. However, the use of the GCI and CQ survey has not been tested in the Department of Civil and Environmental Engineering at the University of Utah for assessing impact of global learning activities. These two extensions of this work will be the subject of future efforts.

\section{Acknowledgement}

The project reported herein was sponsored by the University of Utah, Office for Global Engagement. 


\section{References}

${ }^{1}$ Cheah, C.Y.J., Chen, P.-H., Ting, S.K. (2005). "Globalization challenges, legacies, and civil engineering curriculum reform." Journal of Professional Issues in Engineering Education and Practice, 131(2), 105-110.

${ }^{2}$ Landorf, H., \& Doscher, S.P. (2015). "Defining global learning at Florida International University.” Diversity \& Democracy, 18(3), pp. 1-7.

${ }^{3}$ The University of Rhode Island, $<$ http://web.uri.edu/iep/> (Jan, 2016)

${ }^{4}$ Georgia Tech University, $<$ http://www.ce.gatech.edu/academics/mundy $>($ Jan, 2016)

${ }^{5}$ Kennedy, M. and Jones, S.A. (2015). "Developing global engineering outcomes for BS Graduates." ASEE International Forum, 14 June 2015, Seattle, WA, Paper ID\#14342.

${ }^{6}$ NAFSA, Association of International Educators (2013). Improving and Assessing Global Learning.

${ }^{7}$ McNeill, $\mathrm{N}$ and Cox, M, (2011), "Global engineering programs identifying and supporting a diverse array of learning outcomes." American Society for Engineering Education, AC 2011-323.

${ }^{8}$ Burian, S.J. and Romero, P. (2012). "Engineering study abroad program on sustainable infrastructure combining engineering and non-engineering students." American Society for Engineering Education (ASEE) Annual Conference Proceedings, 10-13 June, 2012, San Antonio, TX, USA.

${ }^{9}$ Chronicle Staff. (2015). "Benefits of study abroad are not universal, paper says," The Chronicle of Higher Education. January.

${ }^{10}$ Nussbaum, M. (2004). “Liberal education and global community.” Liberal Education, 90(4), 42-48.

${ }^{11}$ Hovland, K. (2006). "Shared futures: Global learning and liberal education.” Diversity Digest, 8(3), Association of American Colleges and Universities, Washington D.C., pp. 1, 16-17.

${ }^{12}$ Marcus, R.R., Hayter, D., Koivula, M., and Garcia, A. (2013). Global Learning Inventory 2012-2013. California State University, Long Beach.

${ }^{13}$ Olson, C., Green, M., and Hill, B. (2006). A handbook for advancing comprehensive internationalization: What institutions can do and what students should learn. Washington, DC: American Council on Education.

${ }^{14}$ Stevens, M.J., Bird, A., Mendenhall, M.E., and Oddou, G. (2014). "Measuring global leader intercultural competency: Development and validation of the Global Competencies Inventory (GCI)." In J. Osland, M. Li, and Y. Wang (eds.). Advances in Global Leadership, Volume 8, Bingley, UK: Emerald, pp. 99-138.

${ }^{15}$ Mendenhall, M.E., Arnardottir, A.A., Oddou, G.R., and Burke, L.A. (2013). "Developing cross-cultural competencies in management education via cognitive-behavior therapy." Academy of Management Learning \& Education, 12(3): $436-451$.

${ }^{16}$ Bird, A. and Osland, J.S. (2004). "Teaching cultural sensemaking." In Goodman, R., Phillips, M. and Boyacigiller, N. (Eds.) Crossing cultures: Lessons from master teachers. Beverly Hills, CA: Sage. Pp. 186-207.

${ }^{17}$ Bird, A. and Osland, J.S. (2006). "Making sense of intercultural collaboration." International Journal of Management and Organizations, 35 (4): 115-132. 
${ }^{18}$ Research of the Kozai Group, http://www.kozaigroup.com/research/

${ }^{19}$ University of Utah, Office for Global Engagement, http://global.utah.edu/oge/index.php

${ }^{20}$ Association of International Educators, http://www.nafsa.org

${ }^{21}$ Musil, C.M. (2006). Assessing global learning: Matching good intentions with good practice. Association of American Colleges and Universities.

${ }^{22}$ Cultural Intelligence Center, http://www.culturalq.com/tmpl/home/index.php

${ }^{23}$ American Association of Colleges and Universities https://www.aacu.org/value

${ }^{24}$ Earley, P.C. and Ang, S. (2003). Cultural Intelligence: Individual interactions across cultures. Stanford Business Books, Stanford, CA. 


\section{Appendix A. Global Competency Inventory}

\section{Global Competencies Inventory}

\section{Introduction}

The Global Competencies Inventory (GCI) is designed to assess personal qualities associated with effectiveness in environments where there are cultural norms and behaviors different from one's own. The information contained in this feedback report can provide a basis for understanding both current competencies as well as point to opportunities for future development and growth.

This report focuses on three main factors of intercultural adaptability:

- Perception Management

- Relationship Management

- Self-Management

\section{Background Demographics of Respondent}

List your country and/or region/state that you most identify as your place of origin

List any Job-Related International Experiences that you have had outside of your country of origin

List any Job-Related Intercultural Experiences that you have had within your country of origin 
Place a checkmark at the level at which you think the typical University of Utah Civil and Environmental Engineering student is able to perform at graduation.

\begin{tabular}{|c|c|c|c|c|c|c|}
\hline \multirow{2}{*}{$\begin{array}{l}\text { Perception Management } \\
\text { Considers the processes by which } \\
\text { perceptions and judgments are made, as } \\
\text { well as student's ability to accurately } \\
\text { make sense of ambiguous situations and } \\
\text { to be inclusive of differences. }\end{array}$} & \multicolumn{2}{|c|}{ Low } & \multicolumn{2}{|c|}{ Moderate } & \multicolumn{2}{|c|}{ High } \\
\hline & 1 & 2 & 3 & 4 & 5 & 6 \\
\hline $\begin{array}{l}\text { 1. Nonjudgmentalness } \\
\text { Willingness to withhold or suspend } \\
\text { negative judgments about situations or } \\
\text { people. }\end{array}$ & & & & & & \\
\hline $\begin{array}{l}\text { 2. Inquisitiveness } \\
\text { Disposition to look at new and different } \\
\text { experiences as opportunities for variety, } \\
\text { change, and learning. }\end{array}$ & & & & & & \\
\hline $\begin{array}{l}\text { 3. Tolerance of Ambiguity } \\
\text { Capacity to be comfortable with } \\
\text { ambiguity and uncertainty. }\end{array}$ & & & & & & \\
\hline $\begin{array}{l}\text { 4. Cosmopolitanism } \\
\text { Natural interest in and curiosity about } \\
\text { foreign countries, cultures, and } \\
\text { geography. }\end{array}$ & & & & & & \\
\hline $\begin{array}{l}\text { 5. Interest Flexibility } \\
\text { Willingness to explore new interests or } \\
\text { hobbies and to try things that differ } \\
\text { from your normal routine. }\end{array}$ & & & & & & \\
\hline
\end{tabular}

Adapted from the Kozai Group, Test Form: Version 3.1(6).

http://kozaigroup.com/inventories/the-global-competencies-inventory-gci/ 


\begin{tabular}{|c|c|c|c|c|c|c|}
\hline \multirow{2}{*}{$\begin{array}{l}\text { B. Relationship } \\
\text { Management } \\
\text { Considers level of self-awareness, the } \\
\text { ability to attend to oneself and others, } \\
\text { and the application of sound } \\
\text { interpersonal skills to deal with people } \\
\text { from different cultures or ethnic groups. }\end{array}$} & \multicolumn{2}{|c|}{ Low } & \multicolumn{2}{|c|}{ Moderate } & \multicolumn{2}{|c|}{ High } \\
\hline & 1 & 2 & 3 & 4 & 5 & 6 \\
\hline $\begin{array}{l}\text { 6. Relationship Interest } \\
\text { Awareness of and interest in other } \\
\text { people, especially those who are } \\
\text { different from the student or who come } \\
\text { from other cultures. }\end{array}$ & & & & & & \\
\hline $\begin{array}{l}\text { 7. Interpersonal Engagement } \\
\text { Willingness to take the initiative to } \\
\text { meet and engage others in interactions, } \\
\text { including strangers from other cultures. }\end{array}$ & & & & & & \\
\hline $\begin{array}{l}\text { 8. Emotional Sensitivity } \\
\text { Capacity to read the emotions and } \\
\text { understand the feelings and concerns of } \\
\text { others, as well as respond with empathy } \\
\text { to the circumstances they face. }\end{array}$ & & & & & & \\
\hline $\begin{array}{l}\text { 9. Self-Awareness } \\
\text { Awareness of oneself, one's values, } \\
\text { beliefs, capabilities, and limitations as } \\
\text { well as an understanding of how one's } \\
\text { beliefs, capabilities, and limitations } \\
\text { impact others. }\end{array}$ & & & & & & \\
\hline $\begin{array}{l}\text { 10. Social Flexibility } \\
\text { Capacity to regulate and adapt one's } \\
\text { behavior to fit in and build positive } \\
\text { relationships with others. }\end{array}$ & & & & & & \\
\hline
\end{tabular}

Adapted from the Kozai Group, Test Form: Version 3.1(6).

http://kozaigroup.com/inventories/the-global-competencies-inventory-gci/ 


\begin{tabular}{|c|c|c|c|c|c|c|}
\hline \multirow{2}{*}{$\begin{array}{l}\text { C. Self-Management } \\
\text { Consists of personal traits known to be } \\
\text { essential for effective coping when } \\
\text { faced with the challenges and personal } \\
\text { demands of intercultural situations. }\end{array}$} & \multicolumn{2}{|c|}{ Low } & \multicolumn{2}{|c|}{ Moderate } & \multicolumn{2}{|c|}{ High } \\
\hline & 1 & 2 & 3 & 4 & 5 & 6 \\
\hline $\begin{array}{l}\text { 11. Optimism } \\
\text { Positive mental outlook towards people } \\
\text { and situations generally, and living and } \\
\text { working in a foreign culture. }\end{array}$ & & & & & & \\
\hline $\begin{array}{l}\text { 12. Self-Confidence } \\
\text { Belief in your ability to succeed by hard } \\
\text { work and effort. }\end{array}$ & & & & & & \\
\hline $\begin{array}{l}\text { 13. Self-Identity } \\
\text { Ability to maintain your own values } \\
\text { and beliefs. }\end{array}$ & & & & & & \\
\hline $\begin{array}{l}\text { 14. Emotional Resilience } \\
\text { Emotional strength and ability to cope } \\
\text { well with setbacks, mistakes, or } \\
\text { frustrations. }\end{array}$ & & & & & & \\
\hline $\begin{array}{l}\text { 15. Non-Stress Tendency } \\
\text { Innate disposition to respond with } \\
\text { calmness and serenity to the stressors } \\
\text { you face. }\end{array}$ & & & & & & \\
\hline $\begin{array}{l}\text { 16. Stress Management } \\
\text { Level of active effort to manage } \\
\text { stressors in one's life. }\end{array}$ & & & & & & \\
\hline
\end{tabular}

Adapted from the Kozai Group, Test Form: Version 3.1(6).

http://kozaigroup.com/inventories/the-global-competencies-inventory-gci/ 